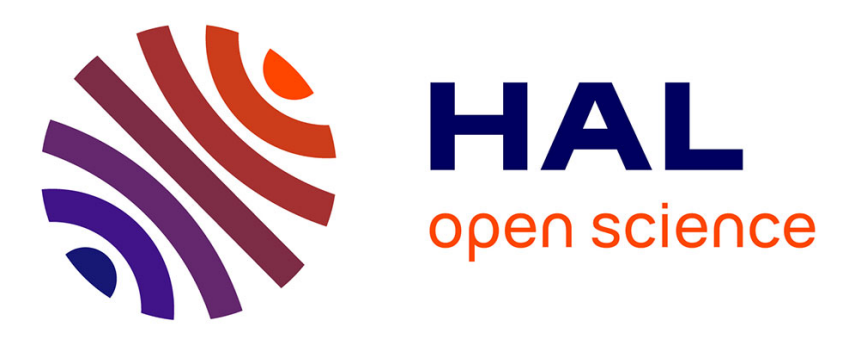

\title{
Gold(I)/Gold(III) Catalysis that Merges Oxidative Addition and $\pi$-Alkene Activation
}

Mathilde Rigoulet, Olivier Thillaye Du Boullay, Abderrahmane Amgoune, Didier Bourissou

\section{- To cite this version:}

Mathilde Rigoulet, Olivier Thillaye Du Boullay, Abderrahmane Amgoune, Didier Bourissou. Gold(I)/Gold(III) Catalysis that Merges Oxidative Addition and $\pi$-Alkene Activation. Angewandte Chemie International Edition, 2020, 59 (38), pp.16625-16630. 10.1002/anie.202006074 . hal03005073

\section{HAL Id: hal-03005073 https://hal.science/hal-03005073}

Submitted on 13 Nov 2020

HAL is a multi-disciplinary open access archive for the deposit and dissemination of scientific research documents, whether they are published or not. The documents may come from teaching and research institutions in France or abroad, or from public or private research centers.
L'archive ouverte pluridisciplinaire HAL, est destinée au dépôt et à la diffusion de documents scientifiques de niveau recherche, publiés ou non, émanant des établissements d'enseignement et de recherche français ou étrangers, des laboratoires publics ou privés. 


\title{
Gold(I)/Gold(III) Catalysis Merging Oxidative Addition and $\pi$-Alkene Activation
}

Mathilde Rigoulet, ${ }^{[a]}$ Olivier Thillaye du Boullay, ${ }^{[a]}$ Abderrahmane Amgoune, ${ }^{[a]}$ Didier Bourissou*[a]

${ }^{[a]}$ CNRS/Université Toulouse III - Paul Sabatier, Laboratoire Hétérochimie Fondamentale et Appliquée (LHFA, UMR 5069)

118 Route de Narbonne, 31062 Toulouse Cedex 09 (France)

E-mail: dbouriss@chimie.ups-tlse.fr

Homepage: http://lhfa.cnrs.fr/index.php/equipes/lbpb/accueil-Ibpb

\section{Keywords: Gold $\bullet$ Homogeneous catalysis $\bullet$ Oxidative addition $\bullet \pi$-Activation $\bullet$ $(P, N)$ Ligand}

\begin{abstract}
:
The hetero-arylation of alkenes with aryl iodides has been efficiently achieved with the (MeDalphos)AuCl complex via Au(I)/Au(III) catalysis. The possibility to combine oxidative addition of aryl iodides and $\pi$-activation of alkenes at gold is demonstrated for the first time. The reaction is robust and general (>30 examples including internal alkenes, 5, 6 and 7-membered rings). It is regioselective and leads exclusively to trans addition products. The $(P, N)$ gold complex is most efficient with electron-rich aryl substrates, which are troublesome with alternative photoredox / oxidative approaches. In addition, it actuates a very unusual switch in regioselectivity from 5-exo to 6-endo cyclization between the $Z$ and $E$ isomers of internal alkenols.
\end{abstract}




\section{Introduction}

Homogeneous gold catalysis is developing extremely fast and is increasingly used in organic synthesis. ${ }^{[1]}$ It offers a unique balance between activity, functional group compatibility and accessible molecular complexity. Research efforts were first focused on reactions involving $\pi$ activation of CC bonds and carbene intermediates, ${ }^{[2]}$ followed by dual gold catalysis in which substrates are concomitantly $\sigma$ and $\pi$-coordinated to two gold centers. ${ }^{[3]}$ The field has been recently further expanded with the advent of $\mathrm{Au}(\mathrm{I}) / \mathrm{Au}(\mathrm{III})$ catalysis. The inherent reluctance of gold to commute between $A u(I)$ and $A u(I I I)$ oxidation states has been overcome using oxidative or photoredox conditions, opening new avenues in cross-coupling catalysis. ${ }^{[4,5]}$ Indeed, the use of external oxidants or light activation has been shown to provide access to aryl Au(III) complexes which can then participate in $\mathrm{C}-\mathrm{C}$ and $\mathrm{C}-\mathrm{X}$ bond-forming reactions. We have recently introduced another approach in which the faculty of hemilabile $(P, N)$ ligands to promote oxidative addition of aryl halides to gold is used to undertake $\mathrm{Au}(\mathrm{I}) / \mathrm{Au}(\mathrm{III})$ catalysis. ${ }^{[6-8]}$ Following the oxidative addition step, we took advantage of the propensity of $\mathrm{Au}(\mathrm{III})$ species to readily $\mathrm{C}-\mathrm{H}$ activate electron-rich arenes $^{[9,10]}$ and thereby achieved for the first time gold-catalyzed $\mathrm{C}-\mathrm{C}$ cross-coupling from aryl halides. Accordingly, a mild, efficient and versatile method for the arylation of indoles with complete C3 regioselectivity was developed (Figure 1). ${ }^{[11]}$ Recently, the approach was further extended to C$\mathrm{N}$ coupling with anilines, amides, sulfonamides and carbamates. ${ }^{[12,13]}$

Gold complexes are extremely powerful in activating $\pi$-bonds and the associated synthetic developments are numerous. Aiming at developing further $\mathrm{Au}(\mathrm{I}) / \mathrm{Au}(\mathrm{III})$ catalysis, we wondered about the possibility to merge oxidative addition of aryl halides and $\pi$-activation of alkenes. ${ }^{[14,15]}$ In this respect, the oxy- and amino-arylation reactions of alkenes, as pioneered by Wolfe et al using Pd catalysis, ${ }^{[16]}$ represent very nice examples of gold redox catalysis under oxidative and photoredox conditions. ${ }^{[17]} \mathrm{As}$ reported hereafter, in the presence of a silver salt and base, the (MeDalphos)AuCl complex [MeDalPhos $\left.=\mathrm{Ad}_{2} \mathrm{P}\left(\mathrm{o}-\mathrm{C}_{6} \mathrm{H}_{4}\right) \mathrm{NMe}_{2}\right]$ was found to efficiently catalyse these transformations from aryl iodides (Figure 1 ) and it shows unique efficiency towards electron-rich aryl substrates, which are problematic with alternative approaches.

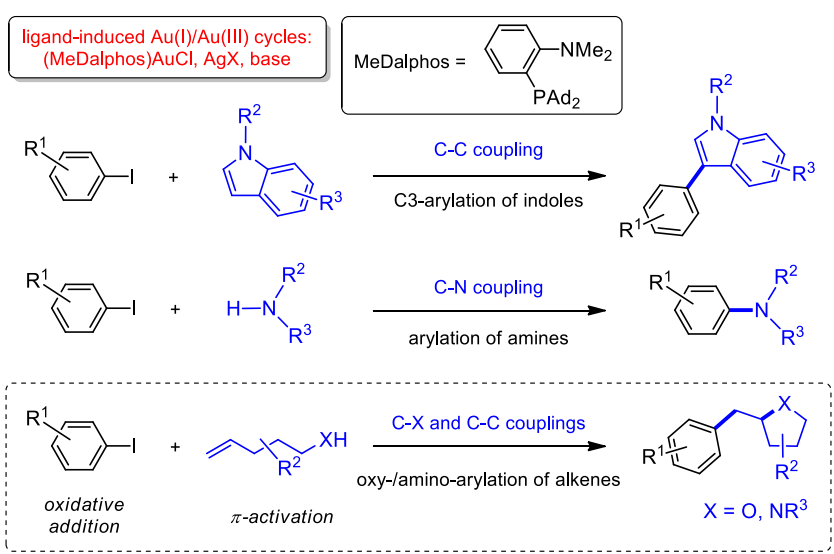

Figure 1. Au(I)/Au(III) catalysis based on oxidative addition of aryl iodides. 


\section{Results and Discussion}

Combining oxidative addition of aryl iodides and $\pi$-activation of alkenes at gold raises issues in terms of compatibility between the involved functional groups and synchronisation of the different steps. The first stage of our study was thus a robustness screen ${ }^{[18]}$ of oxidative addition to gold under stoichiometric conditions. Instantaneous and quantitative oxidative addition occurs when $\mathrm{Phl}$ is added at room temperature to (MeDalPhos)AuCl/AgSbF 6 . The ensuing aryl gold(III) complex 2 displays a diagnostic ${ }^{31} \mathrm{P}\left\{{ }^{1} \mathrm{H}\right\}$ NMR signal at $\delta 74.4 \mathrm{ppm}$. In the presence of 1 equiv of 1-octene, two signals are observed in the ${ }^{31} \mathrm{P}\left\{{ }^{1} \mathrm{H}\right\}$ NMR spectrum (in 77:23 ratio after mixing): the major one at $\delta$ $74.4 \mathrm{ppm}$ corresponds to complex 2 while the other at $\delta 57.9 \mathrm{ppm}$ is associated with the $\pi$-complex (MeDalPhos)Au(1-octene $)^{+} .{ }^{[19]}$ We have recently reported the ability of the $(P, N)$ ligand to form such tricoordinate gold(I) $\pi$-complexes with a variety of alkenes thanks to the faculty of the $\mathrm{N} \rightarrow \mathrm{Au}$ interaction to accommodate the electron demand at gold. ${ }^{[20]}$ NMR Monitoring reveals slow conversion of the $\pi$-complex into the oxidative addition product ( $90 \%$ of complex $\mathbf{2}$ after 4 days), indicating that alkenes slow down but do not prevent the reaction of aryl iodides. It is also noteworthy that no subsequent reaction was noticed between 2 and 1-octene. Similar tests have been performed with 1-pentanol and $N$-tosyl methylamine. ${ }^{[12 b, 21]}$ In both cases, small ${ }^{31} \mathrm{P}$ NMR signals are detected in the typical zone for (MeDalPhos)Au(I) species right after mixing (at $\delta 59.8$ ppm for 1-pentanol and $\delta 64.3 \mathrm{ppm}$ for MeNHTs), but Phl reacts rapidly and oxidative addition is complete within two hours at RT.

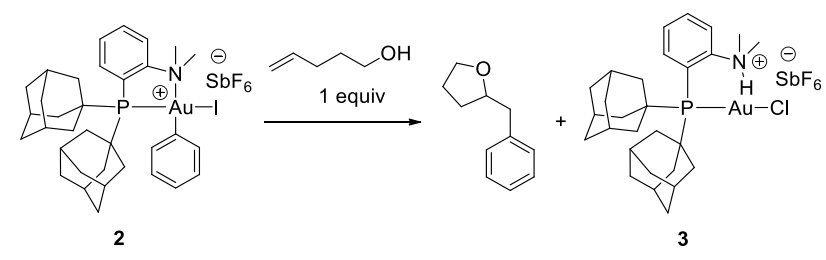

Scheme 1. Stoichiometric oxy-arylation upon reaction of the gold(III) complex 2 with 4-penten-1-ol.

Then, the ability of the gold(III) complex 2 to activate $\mathrm{C}=\mathrm{C}$ double bonds and promote nucleophilic addition was tested. Upon treatment with 1 equiv of 4-penten-1-ol (Scheme 1), it leads to the progressive formation of 2-benzyltetrahydrofurane (the oxy-phenylation product), as deduced from GC-MS and ${ }^{1} \mathrm{H}$ NMR (87\% yield after 2 days at room temperature). ${ }^{31} \mathrm{P}$ NMR spectroscopy reveals the concomitant formation of the cationic gold $(I)$ complex 3, previously authenticated and thoroughly characterized with respect to its unprecedented $\mathrm{N}-\mathrm{H} \cdot \cdots \mathrm{Au}$ hydrogen bonding. ${ }^{[22-24]}$

This result suggests that catalytic turnover may be achieved in the presence of a base and indeed, the $(P, N)$ gold $(I)$ complex proved to efficiently catalyse the oxy-arylation of 4-penten-1-ol with iodobenzene. The reaction parameters (base, solvent, silver salt, ratio of substrates, concentration, catalytic loading) were varied (Tables $\mathrm{S} 1$ and $\mathrm{S} 2)^{[19]}$ to determine the following optimized conditions: $\mathrm{K}_{3} \mathrm{PO}_{4}$ (1 eq.), DCM, $25^{\circ} \mathrm{C}, \mathrm{AgSbF}_{6}$ (1.05 eq.), 1:1 Phl/4-penten-1-ol, $0.4 \mathrm{M}, 5 \mathrm{~mol} \%(\mathrm{P}, \mathrm{N}) \mathrm{AuCl}$.

The scope of aryl iodides was then assessed (Table 1). The oxy-arylation of 4-penten-1-ol works well with a variety of substrates (with an average yield of $88 \%$ over 11 substrates). It tolerates electronwithdrawing groups $\left(p-\mathrm{COCH}_{3}, p-\mathrm{NO}_{2}\right)$ as well as ortho-substitutents $\left(o-\mathrm{OCH}_{3}, o-\mathrm{Ph}\right)$. No sign of $O$ arylation - a possible side-reaction previously observed with electron-poor aryl bromides under palladium catalysis ${ }^{[16 b]}$ - was detected. The reaction actually performs best with electron-rich substrates, as illustrated by the high-yield preparation (>95\%) of the tetrahydrofurane products Igj. Successful incorporation of protected catechol and trihydroxyphenyl moieties (products lh,i) is 
particularly noteworthy, these two motifs being present in a number of biologically active compounds. ${ }^{[25]}$ The preference for electron-rich substrates is a peculiar feature of the $(P, N)$ gold(I) complex. As shown previously, electron-donating substituents activate aryl iodides towards oxidative addition to gold, an electronic bias opposite to that commonly encountered with $\mathrm{Pd}$

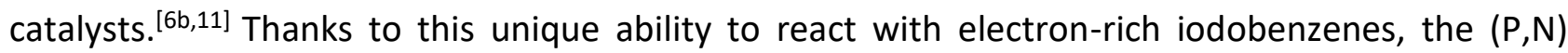
gold(I) complex displays in the oxy-arylation of 4-penten-1-ol a reactivity profile complementary to that observed under photoredox and oxidative conditions, for which electron-rich substrates were found to be problematic due to competitive side-reactions. ${ }^{[5 d, 26]}$

Table 1. Gold-catalyzed oxy-arylation, scope of aryl iodides.

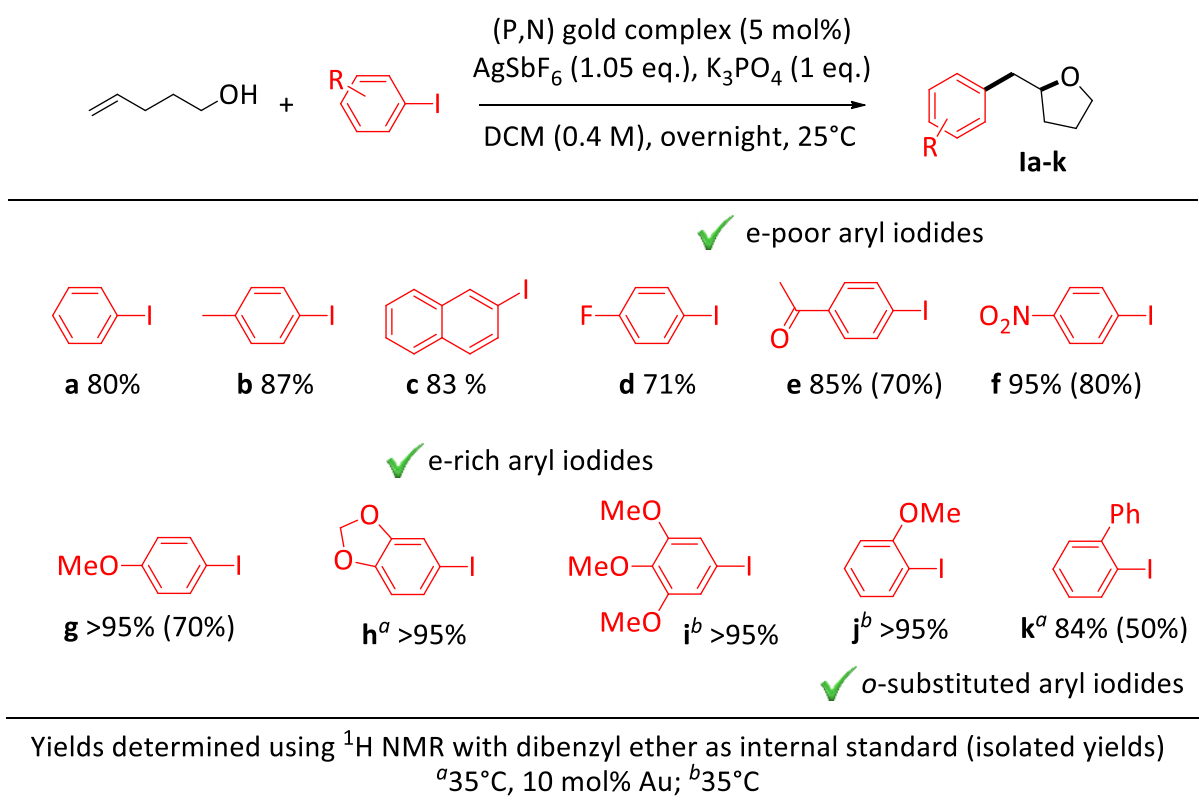


Table 2. Gold-catalyzed oxy-arylation, scope of alkenols.

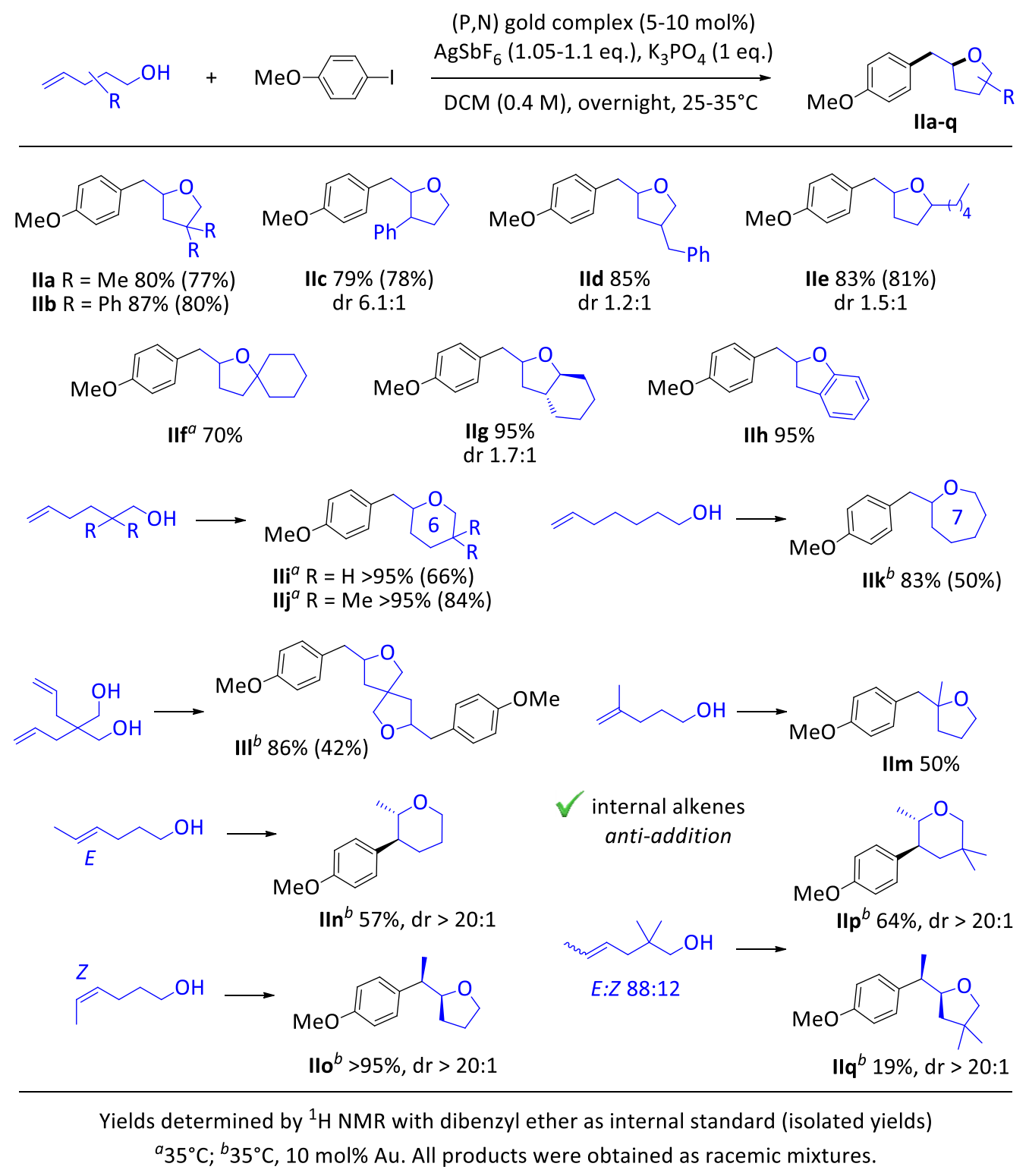

The scope of alkenols was then explored (Table 2). Alkyl and aryl substituents can be introduced on all positions of the tether between the alkene and the alcohol groups (products lla-f). Tetrahydrofuranes fused with cyclohexane and benzene rings (products $\mathbf{I I g}, \mathbf{h}$ ) can also be readily and efficiently obtained. In all cases, the cyclization is fully regioselective and proceeds exclusively in a 5-exo fashion. While modest diastereoselectivities were observed with gold catalysts operating under photoredox or oxidative conditions (1:1 dr ratios in most cases, 2.8:1 at best), ${ }^{[17 a, i, k]}$ a good diastereoselectivity was observed with the $(P, N)$ gold complex for the 3-substituted substrate. The 2,3-disubstituted tetrahydrofurane Ilc was obtained with a dr of 6.1:1. It is possible that the chelation of the $(\mathrm{P}, \mathrm{N})$ ligand to gold induces higher steric shielding and results in better discrimination between the formation of the two diastereomers. Remarkably, lengthening the tether to obtain more challenging $>5$-membered cycles is also possible. Cyclizations proceed smoothly at $35^{\circ} \mathrm{C}$ with 5-hexen-1-ol as well as 6-hepten-1-ol to give the corresponding pyrane and oxepane products IIi,j and IIk, respectively, in high yields. Double oxy-arylation of tetrafunctional substrates is possible too, giving straightforward access to spirocyclic products such as III. Gem- 
disubstituted alkenols are suitable substrates, enabling the formation of quaternary centers (such as in product $1 \mathrm{Im})$, although it requires gentle heating $\left(35^{\circ} \mathrm{C}\right)$ and the associated yield is lower. Substitution in the terminal position (internal alkenes) is also tolerated. Both the $E$ and $Z$ isomers react and in each case, a single product resulting from trans addition (IIn and Ilo, respectively) is obtained (see below for mechanistic implications). Most remarkable is the complete change in regioselectivity between the two isomers. The more reactive Z-substrate undergoes the "normal" 5-exo cyclization, whereas the $E$-substrate reacts via a 6-endo process to give a pyrane ring. ${ }^{[27]}$ To assess the generality of this phenomenon, a $Z / E$ mixture of gem-dimethyl-substituted substrates was tested. Again, the $Z$ isomer was found to exclusively undergo 6-endo cyclization while the $E$ isomer reacted via the classical 5-exo pathway, resulting in a mixture of pyrane IIp and tetrahydrofurane Ilq. The behavior of the $(P, N)$ gold complex markedly contrasts with that observed by Glorius et al combining gold and photoredox catalysis. Here, 5-exo cyclization occurred whatever the stereochemistry of the internal alkenol used as substrate. ${ }^{[17 i]}$ To the best of our knowledge, a complete switch in regioselectivity as observed with the $(P, N)$ gold complex is very unusual and has not been observed either under Pd-catalysis. ${ }^{[16]}$

Table 3. Gold-catalyzed amino-arylation.

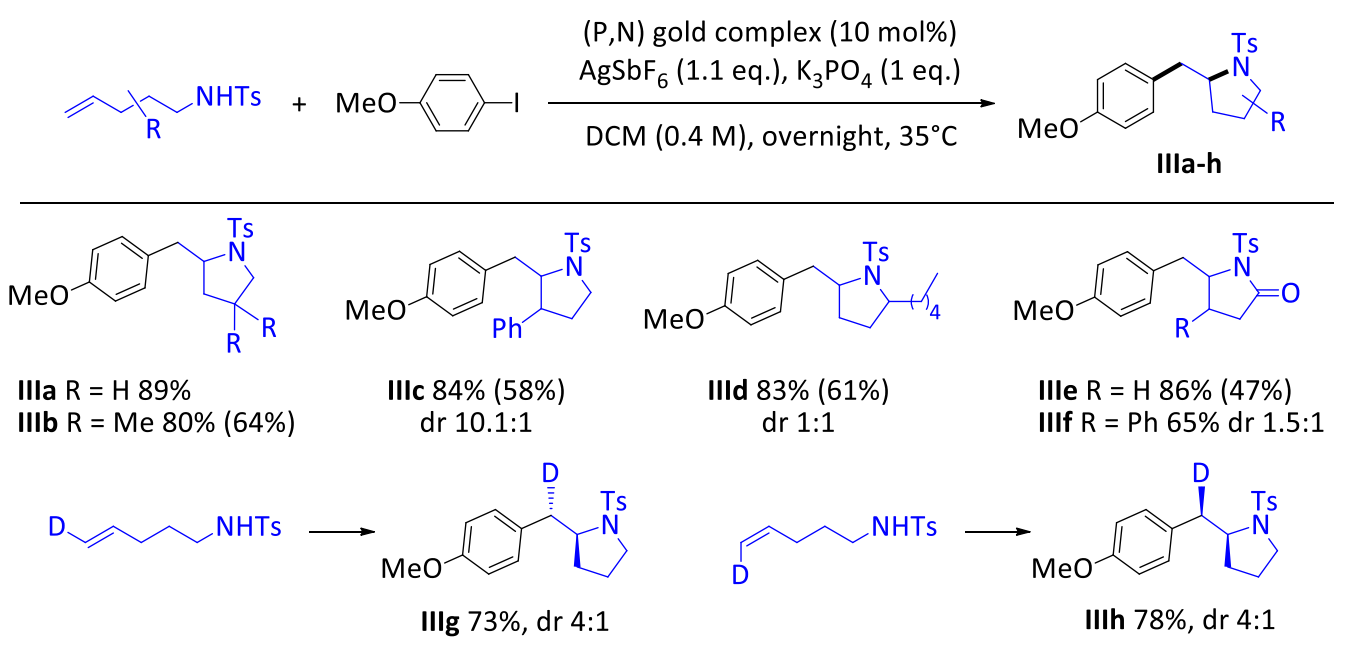

Yields determined by ${ }^{1} \mathrm{H}$ NMR with dibenzyl ether as internal standard (isolated yields)

The robustness and synthetic practicability of the oxy-arylation reaction was then assessed using 4penten-1-ol and $p$-methoxy iodobenzene as substrates. ${ }^{[19]}$ The catalytic loading of $(\mathrm{P}, \mathrm{N}) \mathrm{AuCl}$ was reduced to $2.5 \mathrm{~mol} \%$ without noticeable decrease in the yield of the obtained tetrahydrofurane $\mathbf{I b}$. The reaction does not require drastic precautions. It proceeds with similar efficiency operating under air, using reaction-grade solvents and reagents as received (without specific drying). The reaction could also be smoothly scaled-up to $5 \mathrm{mmol}$ of substrates (instead of $0.4 \mathrm{mmol}$ ). Gratifyingly, amino-arylation reactions also proceed well via the oxidative addition / $\pi$-activation sequence (Table 3). Alkenes featuring an $N$-tosyl amine as well as $N$-tosyl amide moiety in $\gamma$-position are readily converted into the corresponding arylated-pyrrolidines IIIa-d and pyrrolidones IIIe,f increasing the catalytic loading to $10 \mathrm{~mol} \%$ and slightly raising the temperature (to $35{ }^{\circ} \mathrm{C}$ ). Again, the electron-rich $p$-methoxy iodobenzene performs best, substituents are tolerated on all the positions of the tether and strong Thorpe-Ingold effect is not needed for the cyclization to proceed well. In addition, high diastereoselectivity ( $\mathrm{dr}$ 10.1:1) was observed for the formation of the trans2,3-disubstituted pyrrolidine IIIc starting from $N$-tosyl 3-phenyl hex-4-enylamine. 
From a mechanistic viewpoint, two general pathways are conceivable for such hetero-arylation reactions. They involve either migratory insertion of the alkene or outer-sphere attack of the $\mathrm{O} / \mathrm{N}$ nucleophiles as key steps and result in different stereochemical outcomes, respectively syn or anti addition of the $\mathrm{Ar}$ group and $\mathrm{O} / \mathrm{N}$-nucleophiles to the $\mathrm{C}=\mathrm{C}$ double bond. Palladium-catalyzed transformations have been shown to operate mainly by the insertion route (into $\mathrm{Pd}-\mathrm{O}$ bonds), but anti Wacker-type additions have also been observed occasionally. ${ }^{[16]}$ With gold, hetero-arylation reactions were systematically proposed to proceed via the outer-sphere pathway based on the formation of trans addition products, ${ }^{[28]}$ but with different variants. Zhang et al suggested that oxidation and aryl transfer to gold occur first, before the alkenol / alkenamine substrate is activated and cyclized. ${ }^{[17 a]}$ In contrast, Glorius et al proposed that gold(I) initially reacts with the alkenol / alkenamine and promotes cyclization, before the aryl group is added to gold and oxidation to $\mathrm{Au}$ (III) occurs. ${ }^{[17 i]}$ In both cases, the hetero-arylation product is released by reductive elimination. With the (MeDalphos)AuCl complex, the oxy- and amino-arylation reactions are proposed to proceed via the $\mathrm{Au}(\mathrm{I}) / \mathrm{Au}(\mathrm{III})$ catalytic cycle depicted in Figure 2. It starts by oxidative addition of the aryl iodide to gold, based on the faculty of the $(P, N)$ ligand to promote this step even in the presence of alkenes, alcohols and amines. It is also noteworthy that exactly the same catalytic results were obtained in the oxy-arylation of 4-penten-1-ol using the MeDalphos gold(I) complex or the corresponding gold(III) complex 2' deriving from oxidative addition of 4-iodoanisole. ${ }^{[19]} \eta^{2}$-Coordination of the alkene to gold(III ${ }^{[29]}$ would then promote cyclization by nucleophilic addition of the pendant alcohol / amine. The steric crowding induced at gold by the chelating $(P, N)$ ligand may explain the high diastereoselectivity achieved upon formation of 2,3-disubstituted products (tetrahydrofurane Ilc and pyrrolidine IIIc) as well as the switch in regioselectivity from 5-exo to 6-endo cyclization observed between the $Z$ and $E$ isomers of internal alkenols. Finally, reductive elimination at gold would induce the $\mathrm{C}_{\mathrm{sp}} 2-\mathrm{C}_{\mathrm{sp}} 3$ coupling and regenerate the [(MeDalphos)Au $\left.{ }^{+}\right]$active species, which is in equilibrium with the corresponding $\pi$-alkene complex. This scenario is consistent with trans addition across the $\mathrm{C}=\mathrm{C}$ double bond, as apparent from the stereochemistry of the tetrahydrofurane and tetrahydropyrane products IIn-q. Reactions from $D$-labeled $N$-tosyl pent-4-enyl amines leading to pyrrolidine $\mathbf{I I g}, \mathbf{h}$ also support trans addition as the main route for the amino-arylation reaction. ${ }^{[19]}$ Of note, small amounts of the cis addition products were detected in this case, suggesting that the migratory insertion pathway may compete with the outer-sphere nucleophilic attack and contribute to a small extent with such substrates, in line with the feasibility of syn migratory insertion reactions of alkenes into $\mathrm{Au}(\mathrm{III})-\mathrm{C}$ bonds recently substantiated. ${ }^{[30]}$ 


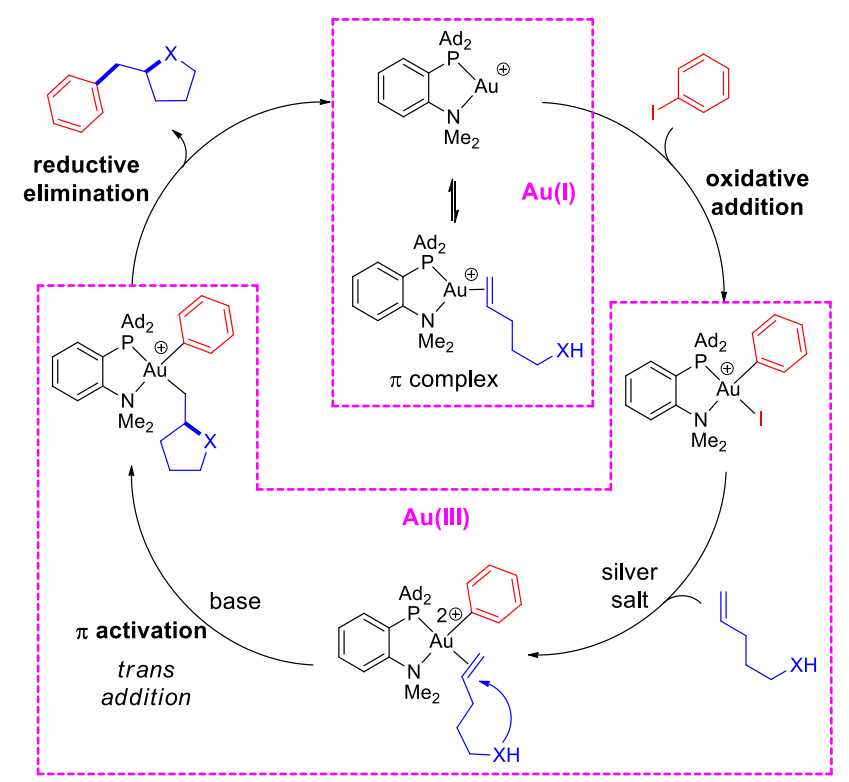

Figure 2. Proposed catalytic cycle for the oxy-/amino-arylation reactions with the (MeDalphos)AuCl complex (counter-anions are omitted).

\section{Conclusion}

In summary, the first gold-catalyzed reaction to combine oxidative addition of aryl iodides and $\pi$ activation of alkenes has been developed. The transformation is efficient and robust. It works with a broad scope of substrates and gives access to 5 , as well as 6 and 7-membered rings. It is based on a ligand-induced approach - using the $(\mathrm{P}, \mathrm{N})$ ligand MeDalphos - that complements and significantly extends the synthetic interest of the oxy-and amino-arylation reactions performed under oxidative / photoredox conditions. The reaction is compatible and actually best-performing with electron-rich aryl substrates which otherwise react sluggishly. The $(P, N)$ ligand brings sterical shielding to gold and induces synthetically useful levels of diastereoselectivity upon formation of 2,3-disubstituted products (dr 6-10:1), surpassing the other gold systems. Also noteworthy and very unusual is the complete switch in regioselectivity from 5-exo to 6-endo cyclization between the $E$ and $Z$ isomers of internal alkenols. Future work will seek to further develop the synthetic potential of this approach.

\section{Acknowledgments}

Financial support from the Centre National de la Recherche Scientifique and the Université de Toulouse is gratefully acknowledged. M.R. thanks MESRI (Ministère de l'Enseignement Supérieur, de la Recherche et de I'Innovation) for her PhD fellowship (Contrat Doctoral Spécifique Normalien). The NMR service of ICT (S. Massou, P. Lavedan and M. Vedrenne) is acknowledged for assistance with the TOCSY experiments.

\section{References}

[1] a) A. S. K. Hashmi, D. F. Toste, Modern Gold Catalyzed Synthesis, Wiley-VCH, Weinheim, 2012; b) F. D. Toste, V. Michelet, Gold Catalysis: An Homogeneous Approach, Imperial College Press, 2014; c) L. M. Slaughter, Ed. , Homogeneous Gold Catalysis, Springer International Publishing, 2015; d) D. Pflästerer, A. S. K. Hashmi, Chem. Soc. Rev. 2016, 45, 1331-1367; e) A. M. Echavarren, A. S. K. Hashmi, F. D. Toste, Adv. Synth. Catal. 2016, 358, 1347-1347.

[2] a) A. Stephen, K. Hashmi, Gold Bull. 2004, 37, 51-65; b) A. S. K. Hashmi, Chem. Rev. 2007, 107, $3180-$ 3211; c) E. Jiménez-Núñez, A. M. Echavarren, Chem. Rev. 2008, 108, 3326-3350; d) R. Dorel, A. M. 
Echavarren, Chem. Rev. 2015, 115, 9028-9072; e) Y. Wang, M. E. Muratore, A. M. Echavarren, Chem. - Eur. J. 2015, 21, 7332-7339; f) Y.-M. Wang, A. D. Lackner, F. D. Toste, Acc. Chem. Res. 2014, 47, 889-901; g) D. Qian, J. Zhang, Chem. Soc. Rev. 2015, 44, 677-698; h) R. J. Harris, R. A. Widenhoefer, Chem. Soc. Rev. 2016, 45, 4533-4551.

[3] a) I. Braun, A. M. Asiri, A. S. K. Hashmi, ACS Catal. 2013, 3, 1902-1907; b) A. S. K. Hashmi, Acc. Chem. Res. 2014, 47, 864-876; c) X. Zhao, M. Rudolph, A. S. K. Hashmi, Chem. Commun. 2019, 55, 12127-12135.

[4] For reviews dealing with redox gold catalysis under oxidative / photoredox conditions, see: a) M. N. Hopkinson, A. D. Gee, V. Gouverneur, Chem. - Eur. J. 2011, 17, 8248-8262; b) H. A. Wegner, M. Auzias, Angew. Chem. Int. Ed. 2011, 50, 8236-8247; Angew. Chem. 2011, 123, 8386; c) M. N. Hopkinson, A. TlahuextAca, F. Glorius, Acc. Chem. Res. 2016, 49, 2261-2272; d) M. D. Levin, S. Kim, F. D. Toste, ACS Cent. Sci. 2016, 2, 293-301; e) Z. Zheng, Z. Wang, Y. Wang, L. Zhang, Chem. Soc. Rev. 2016, 45, 4448-4458; f) M. O. Akram, S. Banerjee, S. S. Saswade, V. Bedi, N. T. Patil, Chem. Commun. 2018, 54, 11069-11083; g) M. Zidan, S. Rohe, T. McCallum, L. Barriault, Catal. Sci. Technol. 2018, 8, 6019-6028; h) A. Nijamudheen, A. Datta, Chem. - Eur. J. 2020, 26, 1442-1487.

[5] For most recent contributions on gold redox catalysis, see: a) A. Dahiya, C. Fricke, F. Schoenebeck, J. Am. Chem. Soc. 2020, DOI: 10.1021/jacs.0c02860; b) C. Fricke, A. Dahiya, W. B. Reid, F. Schoenebeck, ACS Catal. 2019, 9, 9231-9236; c) W. Li, D. Yuan, G. Wang, Y. Zhao, J. Xie, S. Li, C. Zhu, J. Am. Chem. Soc. 2019, 141, 3187-3197; d) X. Ye, P. Zhao, S. Zhang, Y. Zhang, Q. Wang, C. Shan, L. Wojtas, H. Guo, H. Chen, X. Shi, Angew. Chem. Int. Ed. 2019, 58, 17226-17230; Angew. Chem. 2019, 131, 17386-17390; e) J. Xie, K. Sekine, S. Witzel, P. Krämer, M. Rudolph, F. Rominger, A. S. K. Hashmi, Angew. Chem. Int. Ed. 2018, 57, 16648-16653; Angew. Chem. 2018, 130, 16890-16895; f) I. Chakrabarty, M. O. Akram, S. Biswas, N. T. Patil, Chem. Commun. 2018, 54, 7223-7226; g) M. O. Akram, P. S. Shinde, C. C. Chintawar, N. T. Patil, Org. Biomol. Chem. 2018, 16, 2865-2869.

[6] a) M. Joost, A. Zeineddine, L. Estévez, S. Mallet-Ladeira, K. Miqueu, A. Amgoune, D. Bourissou, J. Am. Chem. Soc. 2014, 136, 14654-14657; b) A. Zeineddine, L. Estévez, S. Mallet-Ladeira, K. Miqueu, A. Amgoune, D. Bourissou, Nat. Commun. 2017, 8, 565.

[7] For related work involving (N,N)-chelating ligands, see: a) M. J. Harper, C. J. Arthur, J. Crosby, E. J. Emmett, R. L. Falconer, A. J. Fensham-Smith, P. J. Gates, T. Leman, J. E. McGrady, J. F. Bower, et al., J. Am. Chem. Soc. 2018, 140, 4440-4445; b) Y. Yang, L. Eberle, F. F. Mulks, J. F. Wunsch, M. Zimmer, F. Rominger, M. Rudolph, A. S. K. Hashmi, J. Am. Chem. Soc. 2019, 141, 17414-17420; c) J. A. Cadge, H. A. Sparkes, J. F. Bower, C. A. Russell, Angew. Chem. Int. Ed. 2020, 59, 6617-6621; Angew. Chem. 2020, 132, 6679-6683.

[8] For intramolecular oxidative additions of aryl halides to gold, see: a) J. Guenther, S. Mallet-Ladeira, L. Estevez, K. Miqueu, A. Amgoune, D. Bourissou, J. Am. Chem. Soc. 2014, 136, 1778-1781; b) J. Serra, T. Parella, X. Ribas, Chem. Sci. 2017, 8, 946-952.

[9] For the pioneering contribution, see: M. S. Kharasch, H. S. Isbell, J. Am. Chem. Soc. 1931, 53, 30533059.

[10] For reviews on gold-mediated $\mathrm{C}-\mathrm{H}$ bond activation / functionalisation, see: a) T. C. Boorman, I. Larrosa, Chem. Soc. Rev. 2011, 40, 1910-1925; b) T. de Haro, C. Nevado, Synthesis 2011, 2530-2539; c) S. Gaillard, C. S. J. Cazin, S. P. Nolan, Acc. Chem. Res. 2012, 45, 778-787.

[11] J. Rodriguez, A. Zeineddine, E. D. S. Carrizo, K. Miqueu, N. Saffon-Merceron, A. Amgoune, D. Bourissou, Chem. Sci. 2019, 10, 7183-7192.

[12] a) M. O. Akram, A. Das, I. Chakrabarty, N. T. Patil, Org. Lett. 2019, 21, 8101-8105; b) J. Rodriguez, N. Adet, N. Saffon-Merceron, D. Bourissou, Chem. Commun. 2020, 56, 94-97. 
[13] For the application of oxidative addition of aryl iodides to $(\mathrm{P}, \mathrm{N})$-ligated gold $(\mathrm{I})$ complexes to cysteine arylation (C-S coupling), see: M. S. Messina, J. M. Stauber, M. A. Waddington, A. L. Rheingold, H. D. Maynard, A. M. Spokoyny, J. Am. Chem. Soc. 2018, 140, 7065-7069.

[14] For gold-catalyzed transformations involving $\pi$-activation-induced cyclisation followed by arylation with diazonium salts, see: a) D. V. Patil, H. Yun, S. Shin, Adv. Synth. Catal. 2015, 357, 2622-2628; b) Z. Xia, O. Khaled, V. Mouriès-Mansuy, C. Ollivier, L. Fensterbank, J. Org. Chem. 2016, 81, 7182-7190; c) U. A. CarrilloArcos, S. Porcel, Org. Biomol. Chem. 2018, 16, 1837-1842; d) Z. Xia, V. Corcé, F. Zhao, C. Przybylski, A. Espagne, L. Jullien, T. L. Saux, Y. Gimbert, H. Dossmann, V. Mouriès-Mansuy, et al., Nat. Chem. 2019, 11, 797805; e) S. Taschinski, R. Döpp, M. Ackermann, F. Rominger, F. de Vries, M. F. S. J. Menger, M. Rudolph, A. S. K. Hashmi, J. E. M. N. Klein, Angew. Chem. Int. Ed. 2019, 58, 16988-16993; Angew. Chem. 2019, 131, 1714417149; f) Y. Yang, J. Schießl, S. Zallouz, V. Göker, J. Gross, M. Rudolph, F. Rominger, A. S. K. Hashmi, Chem. Eur. J. 2019, 25, 9624-9628.

[15] During the the final stage of this manuscript preparation, a related work on gold-catalyzed 1,2diarylation of alkenes by Patil and co-workers was published on line: C. C. Chintawar, A. K. Yadav, N. T. Patil, Angew. Chem. Int. Ed. DOI: 10.1002/anie.202002141.

[16] a) J. P. Wolfe, M. A. Rossi, J. Am. Chem. Soc. 2004, 126, 1620-1621; b) M. B. Hay, A. R. Hardin, J. P. Wolfe, J. Org. Chem. 2005, 70, 3099-3107; c) J. S. Nakhla, J. W. Kampf, J. P. Wolfe, J. Am. Chem. Soc. 2006, 128, 2893-2901; d) M. B. Bertrand, J. D. Neukom, J. P. Wolfe, J. Org. Chem. 2008, 73, 8851-8860; e) J. P. Wolfe, in Synth. Heterocycles Met.-Catalyzed React. Gener. One More Carbon-Heteroat. Bonds (Ed.: J.P. Wolfe), Springer, Berlin, Heidelberg, 2013, pp. 1-37.

[17] a) G. Zhang, L. Cui, Y. Wang, L. Zhang, J. Am. Chem. Soc. 2010, 132, 1474-1475; b) A. D. Melhado, W. E. Brenzovich, A. D. Lackner, F. D. Toste, J Am Chem Soc 2010, 132, 8885-8887; c) W. E. Brenzovich, D. Benitez, A. D. Lackner, H. P. Shunatona, E. Tkatchouk, W. A. Goddard, F. D. Toste, Angew. Chem. Int. Ed. 2010, 49, 5519-5522; Angew. Chem. 2010, 122, 5651; d) W. E. Brenzovich, J.-F. Brazeau, F. D. Toste, Org. Lett. 2010, 12, 4728-4731; e) E. Tkatchouk, N. P. Mankad, D. Benitez, W. A. Goddard, F. D. Toste, J. Am. Chem. Soc. 2011, 133, 14293-14300; f) L. T. Ball, M. Green, G. C. Lloyd-Jones, C. A. Russell, Org. Lett. 2010, 12, 4724-4727; g) L. T. Ball, G. C. Lloyd-Jones, C. A. Russell, Chem. - Eur. J. 2012, 18, 2931-2937; h) M. J. Harper, E. J. Emmett, J. F. Bower, C. A. Russell, J. Am. Chem. Soc. 2017, 139, 12386-12389; i) B. Sahoo, M. N. Hopkinson, F. Glorius, J. Am. Chem. Soc. 2013, 135, 5505-5508; j) M. N. Hopkinson, B. Sahoo, F. Glorius, Adv. Synth. Catal. 2014, 356, 2794-2800; k) B. Dong, H. Peng, S. E. Motika, X. Shi, Chem. - Eur. J. 2017, 23, 11093-11099.

[18] a) K. D. Collins, F. Glorius, Nat. Chem. 2013, 5, 597-601; b) K. D. Collins, F. Glorius, Acc. Chem. Res. 2015, 48, 619-627; c) T. Gensch, F. Glorius, Science 2016, 352, 294-295; d) L. Pitzer, F. Schäfers, F. Glorius, Angew. Chem. Int. Ed. 2019, 58, 8572-8576; Angew. Chem. 2019, 131, 8660-8664;

[19] See the Supporting Information for details.

[20] a) M. Navarro, A. Toledo, M. Joost, A. Amgoune, S. Mallet-Ladeira, D. Bourissou, Chem. Commun. 2019, 55, 7974-7977; b) M. Navarro, A. Toledo, S. Mallet-Ladeira, E. D. S. Carrizo, K. Miqueu, D. Bourissou, Chem. Sci. 2020, 11, 2750-2758.

[21] For a structurally characterized (P,N)Au(amine)+ complex, see: K. D. Hesp, M. Stradiotto, J. Am. Chem. Soc. 2010, 132, 18026-18029.

[22] M. Rigoulet, S. Massou, E. D. S. Carrizo, S. Mallet-Ladeira, A. Amgoune, K. Miqueu, D. Bourissou, Proc. Natl. Acad. Sci. 2019, 116, 46-51.

[23] For recent contributions dealing with H-bonding in gold complexes, see: a) H. Schmidbaur, H. G. Raubenheimer, L. Dobrzańska, Chem. Soc. Rev. 2013, 43, 345-380; b) M. Straka, E. Andris, J. Vícha, A. Růžička, 
J. Roithová, L. Rulíšek, Angew. Chem. Int. Ed. 2019, 58, 2011-2016; Angew. Chem. 2019, 131, 2033-2038; c) H. Schmidbaur, Angew. Chem. Int. Ed. 2019, 58, 5806-5809; Angew. Chem. 2019, 131, 5862-5866

[24] lodide to chloride exchange at gold is known to readily occur in dichloromethane with complexes such as 2.[6b,11]

[25] See for example: (a) D.-P. Yang, H.-F. Ji, G.-Y. Tang, W. Ren, H.-Y. Zhang, Molecules 2007, 12, 878$884 ;$ b) A. Flores, M. J. Camarasa, M. J. Pérez-Pérez, A. San-Félix, J. Balzarini, E. Quesada, Org. Biomol. Chem. 2014, 12, 5278-5294.

[26] a) X. Shu, M. Zhang, Y. He, H. Frei, F. D. Toste, J. Am. Chem. Soc. 2014, 136, 5844-5847; b) S. Kim, J. Rojas-Martin, F. D. Toste, Chem. Sci. 2015, 7, 85-88; c) V. Gauchot, A.-L. Lee, Chem. Commun. 2016, 52, 10163-10166; d) V. Gauchot, D. R. Sutherland, A.-L. Lee, Chem. Sci. 2017, 8, 2885-2889; e) S. Witzel, K. Sekine, M. Rudolph, A. S. K. Hashmi, Chem. Commun. 2018, 54, 13802-13804.

[27] The 6-membered ring structures of IIn and IIp were unequivocally attributed based on $1 \mathrm{H}-13 \mathrm{C}$ HSQC/HMBC NMR experiments and comparison with known related compounds.[19]

[28] For an early demonstration of anti-addition upon gold-catalyzed intramolecular diamidation of alkenes under oxidative conditions, see: A. Iglesias, K. Muñiz, Chem. - Eur. J. 2009, 15, 10563-10569.

[29] For a recent review of gold(III) $\pi$-complexes, see: C. Blons, A. Amgoune, D. Bourissou, Dalton Trans. 2018, 47, 10388-10393.

[30] a) F. Rekhroukh, R. Brousses, A. Amgoune, D. Bourissou, Angew. Chem. Int. Ed. 2015, 54, 1266-1269; Angew. Chem. 2015, 127, 1282-1285; b) F. Rekhroukh, L. Estevez, S. Mallet-Ladeira, K. Miqueu, A. Amgoune, D. Bourissou, J. Am. Chem. Soc. 2016, 138, 11920-11929; c) F. Rekhroukh, C. Blons, L. Estévez, S. MalletLadeira, K. Miqueu, A. Amgoune, D. Bourissou, Chem. Sci. 2017, 8, 4539-4545; d) F. Rekhroukh, L. Estevez, C. Bijani, K. Miqueu, A. Amgoune, D. Bourissou, Organometallics 2016, 35, 995-1001; e) J. Serra, P. Font, E. D. S. Carrizo, S. Mallet-Ladeira, S. Massou, T. Parella, K. Miqueu, A. Amgoune, X. Ribas, D. Bourissou, Chem. Sci. 2018, 9, 3932-3940. 
Entry for the Table of Contents

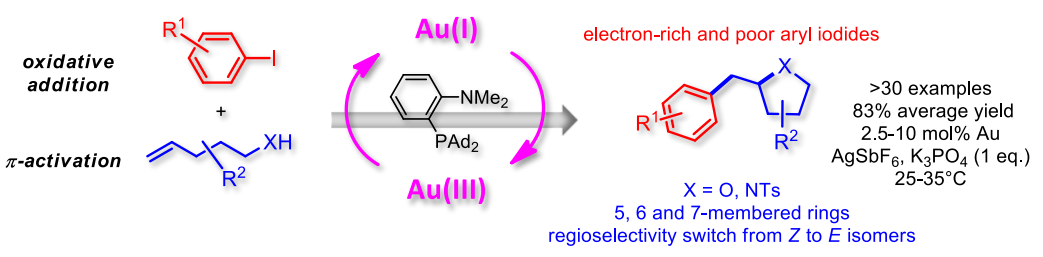

Two-in-one: the (MeDalphos)AuCl complex promotes both oxidative addition of aryl iodides and aactivation of alkenols / alkenamines, and displays a unique profile in catalytic heteroarylation reactions.

Institute and/or researcher Twitter usernames: @LBPB_Lab 